\title{
O QUE A PERSPECTIVA ANTROPOLÓGICA TEM A DIZER SOBRE A AVALLACÃO DE PROJETOS SOCIAIS APOIADOS PELA COOPERACÃO INTERNACIONAL?*
}

\author{
Maria Lúcia de Macedo Cardoso \\ Fundação Oswaldo Cruz - Brasil
}

Delaine Martins Costa

Instituto Brasileiro de Administração Municipal - Brasil

Resumo: $O$ artigo propõe refletir sobre a avaliação de projetos sociais apoiados por agências da cooperação internacional, a partir da perspectiva da antropologia. Situa a cooperação internacional no marco do discurso do desenvolvimento construído no pós-guerra e discute o lugar ocupado pela avaliação nessa arena. Analisa, então, a experiência da avaliação a partir da antropologia seguindo dois eixos: os limites dos padrões institucionalizados pela cooperação internacional baseado no marco lógico para a compreensão do contexto e da mudança social, considerando que os projetos buscam intervir em relações sociais estabelecidas no processo de globalização; e as possibilidades abertas pelo trabalho de campo na avaliação, como espaço de diálogo e ressignificação dos sentidos de mudança social. Ao final, faz uma reflexão sobre a atuação profissional de antropólogos, reafirmando o lugar da etnografia e da teoria como base de formação.

Palavras-chave: avaliação, cooperação internacional, projeto social, trabalho de campo.

Abstract: The present study proposes a reflection, from the viewpoint of Anthropology, on the evaluation of social projects supported by international cooperation agencies. It situates international cooperation in the context of the discourse of development built on post-World War II period, and discusses the role played by projects evaluation in this area. The study then analyses the experience of evaluation, from the

* Agradecemos ao parecerista anônimo de Horizontes Antropológicos pelas valiosas sugestões.

Horizontes Antropológicos, Porto Alegre, ano 20, n. 41, p. 117-140, jan./jun. 2014 http://dx.doi.org/10.1590/S0104-71832014000100005 
standpoint of Anthropology, following two strategies: the limits of the institutionalized patters by international cooperation based on logical frameworks to comprehend the context and social change, considering that the projects aim to intervene in social relationships established in the process of globalization; and the possibilities opened by fieldwork in evaluation as a space for dialog and for imparting new meaning to social change. Last, the study ponders on professional performance of Anthropologists, reaffirming the place of ethnography and theory as the base of the discipline.

Keywords: evaluation, fieldwork, international cooperation, social project.

\section{Sobre as motivacões iniciais}

A gente foi longe demais, o projeto ensinou para a gente e o investimento foi grande. E ele não é de graça, é pago na medida em que a gente muda de vida.

Mulher, quebradeira de coco babaçu. ${ }^{1}$

As reflexões desenvolvidas neste artigo partem de nossa experiência na avaliação de projetos sociais nas últimas três décadas, tanto da prática de gestão como da expertise desenvolvida na realização de avaliações e monitoramentos. Trata-se de projetos implementados por organizações não governamentais (ONGs), movimentos sociais e instituições governamentais em parceria com ONGs ou movimentos sociais, no Brasil e na Bolívia, que receberam financiamento de agências da cooperação internacional. ${ }^{2}$

\footnotetext{
1 Os trechos de depoimentos citados no artigo provêm de entrevistas realizadas em algumas avaliações em que as autoras participaram. Para preservar a identidade dos entrevistados e o sigilo das avaliações, não foram mencionados os nomes nem as instituições às quais pertencem. Da mesma forma, os exemplos de situações de projetos, embora baseados em experiências vivenciadas pelas autoras, também não são identificados para preservar o sigilo das informações relativas aos trabalhos de avaliação realizados.

2 Maria Lúcia de Macedo Cardoso coordenou a avaliação externa de nove projetos executados por instituições, desde a década de 1990, como: Servicios Técnicos para la Mujer - Setam (Bolívia), Ação Educativa (São Paulo), Centro de Cultura Luiz Freire (Pernambuco), Movimento de Organização Comunitária e Movimento das Mulheres Trabalhadoras Rurais - MOC/MMTR (Bahia), Centro das Mulheres do Cabo (Pernambuco), Movimento Interestadual de Mulheres Quebradeiras de Coco Babaçu - MIQCB (Nordeste), e Museu do Folclore Edison Carneiro (Rio de Janeiro); no caso de três projetos, eles envolviam diversas organizações não governamentais de mulheres, de pré-vestibular para negros e de artesãos. Os projetos foram financiados pelas seguintes agências de cooperação: Unifem, Fundação Ford, Organização para a Cooperação Internacional a Projetos de Desenvolvimento - DISOP, ActionAid,
} 
Como projeto social referimo-nos a proposta de intervenção em dada situação que visa produzir mudanças nas relações sociais, em geral, descritas como desiguais e assimétricas. Tem como ponto de partida uma interpretação da situação, que implica uma determinada visão de contexto e uma proposta de mudança, a qual pode ser da perspectiva da organização executora ou da agência de cooperação que está financiando; ou ainda uma interpretação negociada.

As agências da cooperação internacional ${ }^{3}$ que financiam tais projetos atuam em vasto campo de interesses e temas; contudo, uma diretriz comum, particularmente nas últimas duas décadas, é a elaboração de planos de monitoramento e avaliação (PMA) dos projetos e, como parte deles, a realização de avaliações externas, em geral, em períodos intermediários e finais dos projetos.

Há uma gama de instrumentos de monitoramento utilizados pelas organizações executoras dos projetos, ou mesmo exigidos pelas agências financiadoras, os quais, por sua vez, são apropriados e aplicados de forma bastante diferenciada. Os instrumentos mais comuns são relatórios de atividades, registros de presença em reuniões e eventos, fotografias, relatórios financeiros.

Banco Interamericano de Desenvolvimento/Unesco/Ministério da Educação, War on Want e União Europeia, Ministério da Cultura e Banco Nacional de Desenvolvimento Econômico e Social - BNDES. Além dessas avaliações, trabalhou em quatro instituições no planejamento, monitoramento e avaliação de projetos: Servicios Técnicos para la Mujer - Setam (Bolívia), ActionAid Brasil, Centro de Estudos e Ações Culturais e de Cidadania - CEACC e Associação Cultural de Amigos do Museu do Folclore Edison Carneiro - Acamufec. Com exceção de duas avaliações vinculadas a órgãos governamentais, a maioria das experiências refere-se avaliações de projetos locais, realizadas por um profissional, ou uma pequena equipe, em prazos de um a seis meses, incluindo visita ao local do projeto e elaboração de relatório final. Delaine Martins Costa integrou oito equipes de monitoramento e avaliação de projetos governamentais e não governamentais, a partir da década de 1990, tendo coordenado três deles. Um foi apoiado por instituição canadense e envolveu quatro organizações feministas com atuação em áreas urbanas e rural, tendo privilegiado o método qualitativo e o trabalho de campo. Os demais estiveram voltados para análise de políticas públicas e utilizaram instrumentos quantitativos e qualitativos de pesquisa. Três dos projetos foram financiados pela cooperação internacional (Fundo para Igualdade de Gênero - FIG/ Brasil da Agência Canadense para o Desenvolvimento Internacional ACDI/CIDA, Catholic Organisation for Relief and Development Aid - Cordaid e Banco Interamericano de Desenvolvimento - BID), e os demais por organismos governamentais (Prefeituras Municipais, Secretaria Especial de Políticas para as Mulheres - SPM/PR, Secretaria Nacional de Promoção dos Direitos da Criança e do Adolescente - SNPDCA/SDH/PR, Agência Brasileira da Inovação - Finep). A maior parte dos projetos teve escopo nacional, com duração de seis a 12 meses, e contou com equipe multidisciplinar para sua implementação, tendo a autora participado das fases de elaboração da metodologia, sistematização e análise dos dados e elaboração dos relatórios finais.

3 O termo agência de cooperação internacional será analisado em seguida.

Horizontes Antropológicos, Porto Alegre, ano 20, n. 41, p. 117-140, jan./jun. 2014 
A avaliação interna também é comum, e geralmente ocorre uma vez por ano. Em organizações mais estruturadas, essas práticas, em geral, fazem parte da rotina institucional. A avaliação externa, nesses casos, refere-se a projetos específicos e parte de uma exigência da agência que financia.

O consultor, em geral, negocia com a agência o formato da avaliação; pode propor um plano de trabalho, desde que dentro alguns padrões predefinidos pela agência. $\mathrm{O}$ formato mais comum inclui: a) análise da documentação disponível sobre o projeto, incluindo relatórios da organização executora; b) visita a campo para conhecer as intervenções propostas pelo projeto e entrevistar atores envolvidos na execução e/ou beneficiários, além de outros atores interessados no processo de intervenção, como políticos, outras organizações, empresas, etc.; c) análise do material; d) elaboração de relatório preliminar com sugestões; e) apresentação do relatório à equipe executora do projeto e/ ou agência financiadora; f) revisão e elaboração do relatório final. O grau de autonomia do avaliador externo é bastante relativo e sua performance depende, por um lado, da relação de confiança que mantém tanto com a agência financiadora como com a organização executora e, por outro, das exigências da agência em relação aos parâmetros da avaliação. Tivemos experiências muito variadas nesse sentido; desde total confiança e autonomia que impunham cuidado para manter certo distanciamento, até limitação no acesso às informações, tempo extremamente exíguo, contextos políticos complicados e exigência de seguir estritamente o marco lógico do projeto. ${ }^{4}$ Nesses casos, houve pouca flexibilidade para apreender os processos sociais de que acompanhamos in loco, muitas vezes mais complexos do que se poderia supor e que corriam o risco de serem simplificados e reduzidos se não aprofundados ou devidamente registrados na sua amplitude.

A disseminação da avaliação de projetos abriu uma nova área de atuação para cientistas sociais, sobretudo antropólogos, facilitada pelo fato de que esses profissionais já atuavam junto a movimentos sociais e organizações não governamentais nas últimas décadas. Passaram a conviver com outras tradições disciplinares, notadamente, voltadas para a gestão, como é o caso da administração. Mais uma, entre as várias possibilidades de atuação de

4 Mais adiante será explicado o que significa o marco lógico nos projetos sociais.

Horizontes Antropológicos, Porto Alegre, ano 20, n. 41, p. 117-140, jan./jun. 2014 
antropólogos para além da academia, tema ainda marginal de reflexão dentro da própria disciplina ${ }^{5}$.

O pesquisador-avaliador atua como mediador entre as organizações da cooperação internacional e o grupo que executa o projeto - seja uma comunidade, uma associação ou uma ONG - e tem, necessariamente, como eixo de sua pesquisa o PMA do projeto. Nessa prática profissional, o antropólogo depara-se com o desafio de ajustar seu olhar afinado para a cultura local, as relações sociais, as relações de poder e as desigualdades sociais à lógica, ao ritmo e ao tempo dos marcos lógicos e planos de monitoramento e avaliação; de uma interpretação sobre processos e mudanças sociais, para uma análise de efetividade, eficiência, eficácia e resultados. Sobretudo nas duas últimas décadas (1990/2000), tanto as agências governamentais quanto não governamentais têm privilegiado, entre os instrumentos de planejamento, indicadores que demonstrem o alcance de resultados dos projetos. Diferentes metodologias foram inventadas, adaptadas e aperfeiçoadas. No Brasil, uma das mais difundidas refere-se ao marco ou quadro lógico que se constitui numa matriz que sintetiza e associa as principais dimensões do projeto, quais sejam, os objetivos geral e específicos, as atividades a serem desenvolvidas, os resultados a serem alcançados e seus respectivos indicadores, fontes e forma de verificação. Em alguns modelos, o quadro lógico também prevê uma "linha de base" ou "marco zero", que fornece uma caracterização da situação inicial do contexto no qual o projeto irá intervir e que servirá como parâmetro comparativo de avanço ou sucesso do projeto. A metodologia do marco lógico pressupõe o conhecimento dos termos utilizados pelo financiador (por exemplo, como concebe a diferença entre objetivo geral e específico, como conceitua resultados, impactos e efeitos) e a disposição para pensar o a situação-problema a partir desta lógica. Caracteriza-se, portanto, na primeira aproximação com a "lógica de pensamento" dos agentes financiadores, lógica essa estruturante do processo de monitoramento e avaliação, pois irá se constituir no principal instrumento de acompanhamento do projeto, uma vez que produz uma visão

\footnotetext{
5 A reflexão sobre as áreas de atuação de antropólogos, contudo, tem ganhado espaço na última década no país, estimulada inclusive pela própria Associação Brasileira de Antropologia (ABA), em que se relaciona também o debate sobre ética e sobre o ensino de antropologia. Esses reflexões encontram-se em publicações recentes como Antropologia e ética (Víctora et al., 2004), Antropologia extramuros (Silva, 2008) e Experiências de ensino e prática em antropologia no Brasil (Tavares et al., 2010).
}

Horizontes Antropológicos, Porto Alegre, ano 20, n. 41, p. 117-140, jan./jun. 2014 
sintética e direta do que pretende com o financiamento e apoio pleiteados. De forma bastante simplista, ao avaliador cabe examinar e responder aos indicadores previstos (se alcançados ou não) e abstrair os processos sociais e as mudanças como um resultado em si.

Que reflexões trazemos dessas experiências? Quais as contribuições de ordem teórica, metodológica, política e ética para o campo da antropologia? Como proceder uma pesquisa avaliativa dentro dos parâmetros moldados pela cooperação internacional em complexos processos sociais de mudança inseridos num mundo cada vez mais globalizado? Que estratégias metodológicas utilizamos e quais reflexões teóricas são possíveis? Essas são algumas das questões que nos estimularam a escrever o presente artigo. Tocamos apenas em algumas delas.

Iniciamos situando as agências da cooperação internacional no marco do discurso sobre o desenvolvimento construído no pós-guerra, fundamentando a análise a partir de uma abordagem pós-estruturalista, e discutimos o lugar ocupado pela avaliação nesse contexto. Em seguida, fazemos uma reflexão sobre os limites de uma análise a partir da visão fragmentada e parcial que marcos lógicos e indicadores apresentam, considerando que os projetos sociais buscam intervir em contextos sobrepostos de relações sociais estabelecidas no processo de globalização. Posteriormente, refletimos sobre o significado do trabalho de campo antropológico na avaliação de projetos, enquanto espaço de diálogo e ressignificação dos sentidos de mudança social. Ao final, discutimos a avaliação de projetos sociais como área de atuação profissional de antropólogos, entre outras áreas para além da academia.

\section{0 lugar do monitoramento e da avaliação na pauta da cooperação internacional}

Esto es lo que es desarrollo: es una práctica de vincular conocimiento y poder desde una racionalidad completamente distinta a la racionalidad que ha existido en cada lugar. Arturo Escobar (2002, p. 13).

O termo agência da cooperação internacional compreende uma grande variedade de instituições que têm como característica principal a atuação em diversos países, prestando apoio financeiro e/ou técnico a grupos, instituições 
da sociedade civil ou governos. Grosso modo, pode-se classificá-las em três grandes grupos: a) organismos multilaterais de cooperação, vinculados ao sistema da Organização das Nações Unidas (ONU), ou a blocos de países, como a União Europeia; b) agências nacionais de cooperação, vinculadas aos governos nacionais; c) organizações não governamentais internacionais, entre as quais se encontram organizações religiosas, de partidos políticos, ambientalistas, de combate à pobreza, feministas, fundações de grandes empresas e fundações privadas, para citar alguns exemplos. Outras classificações são possíveis, como a apresentada em estudo da Fundação Getúlio Vargas (Mendonça, 2012, p. 9), que sugere também três categorias: cooperação internacional pública para o desenvolvimento, cooperação realizada por empresas privadas e cooperação filantrópico-solidária. Apesar de diferentes recortes, identificamos os mesmos tipos de organizações e, hoje, já se configura um campo de estudo que aborda a atuação das agências de cooperação internacional, enfocando seu papel na governança internacional e dos países, o investimento aportado e, mais recentemente, a manutenção e a saída dessas instituições dos países da América Latina. Destacam-se, na antropologia, as pesquisas sobre a relação dessas instituições com as organizações dos povos indígenas, como o trabalho de Barroso Hoffman (2009).

A cooperação internacional tem origem em dois movimentos distintos, mas que dialogam entre si e remontam ao período pós-Segunda Guerra Mundial: o de reconstrução dos países atingidos pela guerra, e o de ajuda humanitária a países e populações que viviam em condições de extrema pobreza, particularmente as ex-colônias, ambos com fortes marcas ideológicas. A cooperação entre governos tem como marco o Plano Marshall, criado em 1947 pelo governo dos Estados Unidos para reconstrução das economias europeias, com evidente finalidade de inserção das empresas norte-americanas naquele continente e disseminação de seu modelo político-econômico. Na medida em que as economias europeias se recuperam (em alguns casos, mesmo antes), grupos vinculados a instituições religiosas e filantrópicas organizam-se para promover ajuda a populações em situação de pobreza e em desastres, através de contribuições individuais de cidadãos europeus que se identificavam com as causas defendidas. Posteriormente, as fundações ligadas a empresas, estimuladas pelos incentivos fiscais, se expandiram sob a égide da "responsabilidade social”, como parte de suas estratégias de marketing. Fundações 
privadas também imprimem suas marcas em temas ou causas que consideram importante apoiar, como questões ambientais ou feministas.

A cooperação internacional surge no momento histórico em que se produz o discurso do desenvolvimento o qual, como analisa Arturo Escobar (2005, p. 19), embora possua raízes mais profundas na modernidade e no capitalismo, engendrou a concepção de Terceiro Mundo, referindo-se a países da Ásia, África e América Latina. Um amplo aparato institucional transformou o discurso do desenvolvimento em uma efetiva força social, política e econômica, como detalha o autor:

El discurso del desarrollo hizo posible la creación de un vasto aparato institucional a través del cual se desplegó el discurso; es decir, por medio del cual se convirtió en una fuerza social real y efectiva transformando la realidad económica, social, cultural y política de las sociedades en cuestión. Este aparato comprende una variada gama de organizaciones, desde las instituciones de Bretton Woods (p. ej. el Banco Mundial y el Fondo Monetario Internacional) y otras organizaciones internacionales (p. ej. el sistema de la Organización de Naciones Unidas) hasta las agencias nacionales de planificación y desarrollo, así como proyectos de desarrollo a escala local. (Escobar, 2005, p. 19).

O discurso do desenvolvimento tem operado através de dois mecanismos principais, como assinala Escobar: a profissionalização de problemas de desenvolvimento, com o surgimento de conhecimentos especializados, e a institucionalização através de uma rede de organizações. O conhecimento dos especialistas e a prática das instituições operam por meio de projetos e intervenções (Escobar, 2005, p. 19).

Direta ou indiretamente, independentemente das origens ou vinculações, as agendas das organizações da cooperação internacional têm como pano de fundo o discurso do desenvolvimento e, em seus cenários específicos, o contexto econômico, político e social dos países cooperantes. As agências multilaterais, por sua vez, espelham temas e estratégias que estão na agenda da governança global, particularmente, aquelas discutidas nas conferências da ONU. Em outras palavras, o debate sobre o desenvolvimento - em seus diferenciados significados e disputas conceituais - pauta com maior ou menor influência a atuação das organizações governamentais e não governamentais e, por conseguinte, a agenda de financiamento, incluindo-se aí o monitoramento e a avaliação de projetos. 
As conferências internacionais da ONU desempenharam um importante papel na proposição de medidas de cooperação em áreas prioritárias, integrando as esferas estatal e não estatal, ainda que a atuação dos atores ocorra em arenas distintas (Mendonça, 2012, p. 8-9). Os objetivos de desenvolvimento do milênio (ODM), ${ }^{6}$ por exemplo, tornaram-se princípios orientadores para os governos nacionais, definindo estratégias políticas e direcionando linhas de financiamento. Tais agendas internacionais impactaram a lógica da cooperação não apenas entre governos nacionais e organizações internacionais, mas também nas organizações da sociedade civil. Estas, por sua vez, também pautam novas agendas, na medida em que ganham espaço na arena política internacional.

Ora mais impositivas, ora mais democráticas, o que se observa é que há uma ampla circulação de agendas entre agências da cooperação internacional, governos, movimentos sociais, organizações da sociedade civil e empresas privadas. E, pari passu às agendas, segue uma circulação de conceitos - que ora se cristalizam em valores - os quais, ainda que com diferentes origens, interpretados e apropriados de formas diversas, concretizam-se em estratégias de ação comuns. Referimo-nos a conceitos-valores como: empoderamento (empowerment), transparência ou responsabilização (accountability), parceria, trabalho em rede, igualdade/equidade nas relações de gênero ${ }^{7}$ e igualdade/ equidade nas relações raciais. Esses conceitos-valores fazem parte do discurso do desenvolvimento e circulam indiscriminadamente nas esferas acadêmicas, políticas e da cooperação internacional. Polissêmicos, problematizados ou naturalizados, formam uma espécie de matriz a partir da qual os projetos de intervenção são concebidos e julgados.

Embora não seja possível aprofundar a temática do monitoramento e avaliação considerando a intersecção entre a política governamental e a agenda de

6 São oito objetivos definidos na Declaração do Milênio das Nações Unidas, adotada em 2000 por 191 Estados membros, num esforço de sintetizar os acordos internacionais estabelecidos em várias cúpulas mundiais ao longo dos anos 1990: 1) erradicar a extrema pobreza e a fome; 2) atingir o ensino básico universal; 3) promover a igualdade entre os sexos e a autonomia das mulheres; 4) reduzir a mortalidade infantil; 5) melhorar a saúde materna; 6) combater o HIV/Aids, a malária e outras doenças; 7) garantir a sustentabilidade ambiental; e 8) estabelecer uma parceria mundial para o desenvolvimento. A Declaração do Milênio estipula compromissos concretos a serem alcançados até o ano de 2015, monitorados por indicadores quantitativos.

7 Sobre a questão de gênero nos projetos de desenvolvimento ver os artigos de Costa (1996), Costa e Neves, G. H. (1996) e os artigos reunidos em Costa e Neves, M da G. R. (1995, 1997).

Horizontes Antropológicos, Porto Alegre, ano 20, n. 41, p. 117-140, jan./jun. 2014 
cooperação internacional (o que requer outro artigo), é fundamental observar que esses conceitos-valores também fazem parte do sistema de significado das políticas públicas e merecem estudo específico para esse campo que origina e consolida uma linguagem recente (a partir de 1980) no âmbito governamental com práticas profissionais, departamentos e carreiras que se estruturam para essa finalidade e tendem a ser apropriados por contextos democráticos de gestão, incluindo assim novos termos na racionalidade normativa e nos modos de regulação das populações. ${ }^{8}$ Como analisado por Shore e Wright (1997, p. 1), "[...] an anthropological approach to policy treats the models and language of decision-makers as ethnographic data to be analysed rather than as frameworks for analysis”. O que importa assinalar é que tanto no campo da cooperação internacional quanto no governamental (e poderíamos arriscar que também no setor privado que se dedica à gestão de projetos de responsabilidade social) um conjunto de conceitos-valores estrutura a prática de monitoramento e avaliação que, por sua vez, cria um corpus de especialistas cujas práticas passam a se consolidar, desdobrar e multiplicar em disciplinas de cursos, certificações, carreiras e literatura específicas; mais do que conceitos-valores, estes passam a representar uma técnica a ser aprendida e aplicada. ${ }^{9}$

Em pesquisa sobre a cooperação internacional no Brasil realizada pela Fundação Getúlio Vargas, citada anteriormente, considera-se que novos padrões foram estabelecidos nessas parcerias:

De modo a garantir resultados eficazes e coerentes às metas estabelecidas, novos padrões mais rigorosos foram desenvolvidos. Estados e organizações da sociedade civil atendem, hoje, a uma série de critérios que determinam o caráter dessas parcerias. Diagnósticos, elaboração de projetos e mecanismos de avaliação tornaram-se condições elementares para o financiamento de projetos. (Mendonça, 2012, p. 9).

8 É especialmente notável o fato de 2015 ser dedicado ao Ano Internacional da Avaliação, tal como explicitado pelo EvalPartners (2013), movimento global para fortalecer as capacidades nacionais para avaliação. No Brasil, entre outros, existe a Rede Brasileira de Monitoramento e Avaliação (http://redebrasileirademea.ning.com), que publica a Revista Brasileira de Monitoramento e Avaliação (2011, 2012, 2013). Na área de gênero, o portal Gender Equality Evaluation Portal da ONU Mulheres disponibiliza 350 avaliações já realizadas no mundo (http://genderevaluation.unwomen.org).

9 O artigo de Faria (2005) traça com precisão um mapa das diferentes formas de utilização da avaliação no âmbito das políticas públicas.

Horizontes Antropológicos, Porto Alegre, ano 20, n. 41, p. 117-140, jan./jun. 2014 
Mais que um "padrão rigoroso", como citado na pesquisa, consideramos que a avaliação é um desses conceitos-valor no discurso do desenvolvimento, coadunada com outros como: planejamento, monitoramento e avaliação (PMA); efetividade, eficácia e eficiência; diagnóstico, indicadores e marco lógico.

De forma esquemática, podem-se identificar duas origens diferentes para que a avaliação tenha se tornado uma estratégia indiscutível na cooperação internacional. Por parte das organizações não governamentais filantrópicas e solidárias, que dependem da doação de cidadãos que se identificam com as causas que defendem e projetos que apoiam, a avaliação está estreitamente relacionada com o conceito-valor de transparência, isto é, avalia-se para demonstrar a seus doadores que os objetivos propostos no projeto foram atingidos e, portanto, que os recursos foram adequadamente utilizados; trata-se de uma prestação de contas para os doadores. A outra origem vem da administração, tanto privada como pública, em que o monitoramento e a avaliação visam identificar a relação custo-benefício dos recursos empregados e os gargalos do desenvolvimento do projeto para uma gestão mais eficiente. ${ }^{10}$ Embora com motivações diferentes na sua origem, o papel que a avaliação desempenha nessas organizações assemelha-se cada vez mais. Está orientada por uma visão de gestão voltada para resultados, para medir a eficácia, eficiência e efetividade do projeto, voltada principalmente para uma análise quantitativa, com o objetivo de prestar contas aos doadores e, mais raramente na prática (embora presente no discurso), para orientar mudanças na condução do projeto.

Há certo consenso no discurso das organizações da cooperação internacional sobre a necessidade da avaliação dos projetos pelos seguintes motivos: verificar em que medida os objetivos propostos foram atingidos, compreender como o projeto alcançou ou não seus objetivos, identificar o quanto o projeto foi eficiente na utilização dos recursos para desenvolver as atividades, avaliar o quanto o projeto foi significativo e sustentável para os participantes, e informar os tomadores de decisão sobre como melhorar o projeto. A avaliação externa,

\footnotetext{
10 No campo semântico da cooperação internacional podemos sintetizar: eficiência refere-se à capacidade de produzir resultados com dispêndio mínimo de recursos e esforços; eficácia remete à capacidade de alcançar os objetivos e metas definidos em determinado projeto ou programa; e efetividade diz respeito aos efeitos dos resultados alcançados do projeto/programa a médio e longo prazo sobre a população-alvo. As definições apresentam nuanças conforme as agências de financiamento, se governamentais ou não governamentais. No caso do governo brasileiro, uma das principais referências encontra-se no Manual de auditoria operacional do TCU (Tribunal de Contas da União, 2010).
}

Horizontes Antropológicos, Porto Alegre, ano 20, n. 41, p. 117-140, jan./jun. 2014 
particularmente, isto é, aquela realizada por um consultor que não atua no projeto ou nas instituições envolvidas - portanto, portador de suposta neutralidade - contribui para dar legitimidade ao investimento feito no projeto.

É de se esperar que haja uma diversidade de modelos e práticas de avaliação, em que estão em jogo os tipos de instituição, as concepções de gestão, os temas focados e, como invólucro mais amplo, os discursos de desenvolvimento. Mas, dificilmente, não há como fugir da proposta de intervenção do projeto, seus objetivos e atividades, e do diagnóstico inicial a partir do qual o projeto foi concebido. Esse é o ponto de partida da avaliação.

Ocorre, no entanto, que há um pecado original. A tarefa de elaboração de projeto é considerada uma expertise na cooperação internacional. É detentora de uma linguagem própria, dominada por poucos, e que tem sotaques diferentes de acordo com a agência que financia. Elaborar um projeto é um processo criativo que exige, mais que um domínio da situação que se irá intervir, um domínio da linguagem. Portanto, sustenta-se também sobre um terreno escorregadio; nas agências que não têm regras - e controladores das regras - tão estritas, o projeto constitui apenas um documento formal, necessário para selar uma parceria. Papel semelhante desempenham os planos de monitoramento e avaliação e seus irmãos, os marcos lógicos. A exigência de plano de monitoramento e avaliação e de marco lógico torna imperativo pensar o projeto (e sua ideia principal orientada para um processo de mudança social) esquematizado em objetivos, atividades, resultados esperados, recursos, indicadores de efetividade, eficiência e eficácia.

O plano de monitoramento e avaliação e muitas vezes o marco lógico (quando exigido) são tomados como verdade ou como um dos discursos produzidos sobre o projeto e, portanto, sujeitos à interpretação; na prática, constituem parâmetros a partir dos quais se procederá à avaliação. Desenhados numa lógica cartesiana e positivista, caracterizam-se pela fragmentação do processo social, destacando variáveis isoladas, não permitindo uma visão sistêmica, integrada, contextualizada e processual da realidade sobre a qual o projeto incide e intervém. Dito de outro modo, o plano de monitoramento e avaliação torna-se uma metanarrativa sobre o projeto cujos objetivos para serem alcançados devem ser descritos em indicadores que, passíveis de monitoramento, resultarão na sua consecução e, por conseguinte, na avaliação de que os recursos foram apropriadamente gastos para a finalidade e metas propostas. Coerente com essa visão de mundo, predominam os indicadores 
e os instrumentos de coleta de dados quantitativos. Em geral, o pragmatismo associado ao curto prazo de tempo para avaliação compromete a pertinência da utilização de métodos exclusivamente qualitativos e etnográficos, embora haja um esgotamento na crença de que os indicadores quantitativos sejam suficientes para medir e demonstrar o alcance dos processos de mudança social dada sua complexidade, especialmente, na sociedade brasileira marcada por intensa desigualdade econômica e social. Nesse caso, para o antropólogo, instaura-se um dilema profissional: para empreender a "pesquisa-avaliativa" nos moldes propostos pela cooperação internacional é necessário limitar a possibilidade de diálogo com a teoria social. Autores como Minayo (2004), Minayo e Deslandes (2002) e Minayo et al. (2005) vêm trabalhando a questão, a partir de pesquisas-avaliativas mais amplas, utilizando a triangulação de métodos, isto é, a complementação de abordagens qualitativas com quantitativas associadas a uma interpretação baseada na teoria social.

\section{Nos interstícios dos marcos lógicos: a compreensão do contexto e da mudança em tempos de globalizacão}

A tarefa de uma teoria dos processos sociais consiste no diagnóstico e na explicação das tendências de longo prazo e não planejadas. [...] A recepção de uma tal abordagem teórica vem sendo dificultada pela autocompreensão

da sociologia contemporânea como uma disciplina primordialmente orientada para o presente, que investiga as transformações e as relações de curto prazo no interior de sistemas sociais dados. Essa autocompreensão é uma consequência da divisão acadêmica entre história e sociologia, mas

também da proximidade crescente da sociologia com a prática, ou seja, sua inclusão em projetos de planejamento burocraticamente controlados. Com isso, acaba-se por não compreender o processo de desenvolvimento não-planejado e de longo prazo, que produziu as condições para a prática de planejamento de nossos dias e ao qual todo desenvolvimento social planejado continua intrinsicamente ligado.

Norbert Elias (2006, p. 197).

O texto de Elias (2006), escrito em 1977, é preciso ao identificar a dificuldade da Sociologia para compreender os processos sociais não apenas pela sua preocupação com o presente, mas pela proximidade com a prática, isto é, 
com “projetos de planejamento burocraticamente controlados”, ficando fora de seu campo de análise o que não foi previsto, processos de mudança que ocorrem no longo prazo.

Ao se iniciar uma avaliação, a primeira questão que se apresenta ao avaliador é: qual o contexto social do projeto? Aparentemente, a resposta é simples, mas ao mesmo tempo complexa: as relações sociais sobre as quais o projeto incide. Identificar as relações sociais e, particularmente, as relações de poder torna-se uma primeira atividade cujos limites são impostos, entre outros fatores, pelo tempo e recursos dedicados à condução da avaliação e ao escopo do projeto a ser avaliado. Essas relações preexistem ao projeto, cabendo à própria metodologia empregada na avaliação circunscrever o contexto social no qual se inserem e analisar o alcance dos efeitos do projeto sobre elas.

Complementando o que aponta Elias, o historiador Jacques Revel (1998, p. 27) lembra-nos que as ciências sociais fazem um uso "cômodo e preguiçoso" da noção de contexto, identificando três tipos:

Uso retórico: o contexto, em geral apresentado no início do estudo, produz um efeito de realidade em torno do objeto da pesquisa. Uso argumentativo: o contexto apresenta as condições gerais nas quais uma realidade particular encontra seu lugar, mesmo que nem sempre se vá além de uma simples exposição dos dois níveis de observação. Uso interpretativo, mais raro: extraem-se às vezes do contexto as razões gerais que permitiriam explicar situações particulares.

Afirma, então, que a abordagem micro-histórica recusa a evidência que faz uso do contexto como unificado e homogêneo e propõe constitui-lo a partir da pluralidade necessária à compreensão dos comportamentos que são objeto de observação; essa contextualização múltipla parte do princípio de que cada ator histórico participa, de maneira próxima ou distante, de processos (e se inscreve em contextos) de dimensões e de níveis variáveis, do mais local ao mais global, não existindo hiato entre histórica local e história global (Revel, 1998, p. 27-28).

Escobar (2002, p. 10) também nos lembra, citando Giddens, que a modernidade consiste na descontextualização, em arrancar a vida local de seu contexto, a qual é produzida cada vez mais pelo translocal; a globalização, para Giddens, é a universalização da modernidade.

A compreensão do contexto de um projeto social, com o objetivo de analisar os efeitos produzidos pela intervenção proposta, torna-se, portanto, algo complexo, repleto de matizes objetivos e subjetivos na relação entre o local e

Horizontes Antropológicos, Porto Alegre, ano 20, n. 41, p. 117-140, jan./jun. 2014 
o global, ora como parte de longos processos de mudança social. Facilmente caímos em um dos usos cômodos que aponta Revel (1998).

Lembramo-nos, por exemplo, de uma camponesa aimará, no altiplano boliviano, preocupada com os efeitos que a fumaça produzida pela queima de poços de petróleo no Oriente Médio (nos anos 1980) poderia produzir em seu rebanho bovino. O projeto tratava da melhoria genética do rebanho para aumentar e melhorar a produção de leite. Não que a análise do contexto devesse incluir o Oriente Médio, mas seria importante considerar o acesso aos meios de comunicação, a interpretação de suas informações e a reelaborações simbólicas produzindo ações concretas na vida social. Nem o uso retórico, argumentativo ou mesmo interpretativo dariam conta desse contexto. Teríamos que olhar para um processo mais amplo em que circulam informações e significados, reinterpretados, apropriados de maneiras diversas e que produzem efeitos nas relações sociais. Caso contrário, como entender o medo dessa agricultora?

Já no caso do movimento de mulheres quebradeiras de coco babaçu, no Norte e Nordeste do Brasil, a inserção do óleo de babaçu no mercado internacional - também outro aspecto da globalização - e o projeto de lei que tramita no Congresso Nacional para o livre acesso ao babaçu fazem parte, objetivamente, do contexto de qualquer projeto que envolva esse grupo. Não se podem analisar os efeitos da compra de uma máquina para produzir óleo de babaçu, sem compreender a inserção do óleo no mercado internacional; por mais que as cadeias produtivas sigam caminhos diferentes, elas se encontram, mesmo que simbolicamente, como argumento para afirmação da identidade social dessas mulheres, de sua diferença.

A questão que fica para o avaliador é: até onde estudar e conhecer o contexto, num prazo restrito no qual, em geral, estão circunscritas as avaliações?

Se entramos no jogo dos marcos lógicos e buscamos observar as mudanças que ocorreram a partir do projeto, nos deparamos com três grandes limitantes: a ausência ou precariedade de informações a respeito da situação inicial sobre a qual o projeto interviu; a fragmentação dos indicadores que apontam como se irá verificar a mudança provocada pelo projeto; e o necessário isolamento do contexto em que o projeto se insere. Extrair do processo social exclusivamente aqueles elementos sobre os quais o projeto incide é extremamente artificial não apenas para a compreensão, mas para os próprios sujeitos que o vivenciam. Como disse uma agricultora: "O movimento adquiriu de tudo um pouco dentro do projeto.” Não há limites marcados. Soma-se 
ainda o fato de que os grupos sociais que executam tais projetos serem também financiados por outras agências, com outros projetos. Como diferenciar? Como produzir resultados mensuráveis para prestar contas às agências financiadoras, para computar em suas estatísticas, se as intervenções são realizadas pelos mesmos sujeitos, imbricadas nos mesmos processos sociais?

Se, por um lado, isso indica certa contradição nos instrumentos de monitoramento e avaliação, por outro, abre uma brecha para que nós, cientistas sociais e, particularmente, antropólogos, ampliemos nossas possibilidades de interpretação. Vejamos um exemplo. Um dos objetivos de dado projeto é "reduzir a dependência de intermediários na comercialização de produtos agrícolas” e, como indicador de resultado está foi descrito "o aumento em $20 \%$ os produtos processados pelos agricultores”. Ora, isso é absolutamente fictício por diversos motivos: não há como quantificar a "dependência de intermediários”, há uma diversidade de níveis de dependência entre os próprios agricultores, e o aumento de $20 \%$ é totalmente arbitrário, afinal, como se sabe que esse aumento será um indicativo para se romper com a dependência ou simplesmente uma margem possível? Se nos limitamos a fazer uma avaliação com base em parâmetros como esse, será de grande angústia e inócua, do ponto de vista de uma análise de mudança social. Entretanto, terá cumprido seu papel de produzir dados concretos, quantitativos e mostrar resultados que apontam um progresso unidirecional e em base a parâmetros externos (nesse caso, dos financiadores). A comercialização direta de produtos agrícolas tem de ser analisada dentro de um contexto amplo de relações sociais em que a dependência de intermediários é um dos elementos. Ao mesmo tempo, compreender como se constitui a rede de intermediários e os fatores que configuram a situação de dependência não necessariamente são aspectos que levarão ao aumento de $20 \%$ dos produtos processados pelos agricultores e vice-versa.

Há outro aspecto muito caro a nós, antropólogos: o contexto cultural específico do grupo que executa o projeto. O desconhecimento por parte do avaliador pode levar a distorções grosseiras como certo caso que presenciamos. $\mathrm{O}$ objetivo principal do projeto era melhoria da qualidade do leite produzido por um grupo de agricultoras para que pudessem vender o leite diretamente e não fazer queijos, já que isso significaria um incremento na renda familiar. Uma das estratégias era a mudança na ração das vacas. A avaliação externa do projeto foi realizada por consultores estrangeiros que, entre outras coisas, se dedicaram a medir e contabilizar a produção do vegetal para ração, introduzido pelo projeto, 
e sua relação com o aumento da produção de leite, um indicador quantitativo. No entanto, uma das consequências do uso da ração é que os animais produziam fezes de "má qualidade”, segundo os agricultores, já que não poderiam utilizá-la para queima como combustível por apresentarem um baixo nível de fibra. O contexto local, objetivamente, tinha outras camadas: o gado não servia apenas para produzir leite, mas também para produzir combustível. Esse resultado, nefasto para a comunidade, não foi observado pelos avaliadores, que olhavam o indicador - aumento da produção de leite - de forma isolada. A mudança introduzida não afetava apenas um aspecto da economia dessa sociedade, mas diversos outros não dimensionados, não observados, não avaliados.

A análise do contexto deve ser feita de tal modo que permita olhar de forma integrada para o local, e para as relações entre o local e o global, que, adotando uma perspectiva pós-estruturalista, permita perceber as mudanças como ressignificações. Isso implica voltar o olhar para além dos resultados objetivos, para além do próprio escopo de um projeto. A pergunta passa a ser em que medida o projeto contribuiu para reconhecer o local e estabelecer novas possibilidades de diálogo de conhecimentos, mudando a perspectiva na qual os participantes do projeto são considerados apenas como "receptores" de novos conhecimentos. Nesse sentido, os instrumentos teórico-metodológicos da antropologia, ainda que não aplicados na sua forma canônica, permitem penetrar pelos interstícios dos marcos lógicos e desvendar outras camadas do processo de mudança social sobre o qual o projeto propõe intervir.

\section{0 trabalho de campo da avaliação: uma breve etnografia é possivivel}

Foi uma surpresa esse momento aqui, fazer uma avaliação [...], encontrar as pessoas que apoiam a gente, que são as pessoas que não deixam a gente nem tímida. Porque tem pessoa que faz a entrevista e a gente nem sente, faz uma avaliação com a gente, uma entrevista, que a gente até se sente uma pessoa, assim, capaz.

Mulher, quebradeira de coco babaçu.

A metodologia das avaliações inclui um trabalho de investigação que, em geral, se limita a visitas ao local onde o projeto foi implementado, associado a entrevistas com participantes do projeto. Na nossa experiência, esse é o 
momento em que o exercício do fazer antropológico tem maior possibilidade de se realizar. O tempo é curto, as visitas aos grupos são limitadas, mas sempre é possível observar, conversar informalmente e fazer entrevistas abertas. O diálogo e o encontro acontecem. Rompe-se com o marco lógico, os indicadores, e parte-se para o diálogo. Um roteiro de entrevistas é fundamental, mas impossível se limitar a ele.

À diferença de um trabalho de campo tradicional, em que o antropólogo respeita o tempo social necessário para se aproximar, identificar informantes-chave e buscar mediadores, essa etapa, aqui, é simplesmente suprimida. Pior, entramos em campo tachados de "avaliador", que, entre outros significados, está o da pessoa que aprova financiamento, que vai julgar o projeto e o trabalho daqueles que o executaram. Essa identificação tem uma margem de interpretação, com matizes de estigma que podem provocar reações como medo e insegurança, levando a diálogos nem sempre fluidos. É nesse momento que as lições da antropologia são fundamentais: estabelecer o diálogo a partir do Outro e reconhecer que o encontro, em si, produz novos significados. Como diz a mulher citada na epígrafe acima, "não deixam a gente nem tímida [...] a gente até se sente uma pessoa capaz”. Esse diálogo, permeado por uma relação de poder dada de antemão, pode ocorrer sobre outras bases. Mas o "nem” e o "até" significam também que, na maioria das vezes em que ocorrem diálogos similares, a hierarquia e a relação de poder é o ponto de partida.

Em projetos com marcos lógicos frágeis e ausência de diagnósticos iniciais, a exigência de dados quantitativos se esmorece. Assim, é nesse vácuo que o diálogo com o grupo envolvido no projeto e com atores sociais-chave no contexto considerado acontece, e no qual se buscará compreender as percepções de mudança. Um diálogo reflexivo, que leve o Outro a identificar as diferenças que fizeram a diferença, na definição de Bateson (1972) de mudança, em que se recorre à memória para compreender a trajetória e os significados da situação de hoje. É nesse momento, muitas vezes, que se vislumbra a percepção da mudança, tanto na dimensão individual como coletiva. Esse jogo com a memória dos sujeitos, que o avaliador propõe que joguem, exige sensibilidade para ler os silêncios, as inseguranças, as explosões emocionais e as indiferenças como repletos de significados. Para desenhar cenários imaginários do "antes e do depois", do "se não tivesse isso", ou "do que poderia ser se...”, do que se pode fazer, do que é necessário. O diálogo se dá em base de vivências ressignificadas pela memória, e pelos elementos que são evocados 
no jogo das possibilidades imaginadas. A capacidade de imaginar significa a capacidade de articular elementos de diversos contextos, de avaliar sua (individual ou coletiva) condição de fazer diferente apropriando-se do novo em diálogo e recolocando-se em nova posição de poder. O discurso de uma mulher quebradeira de coco babaçu, produzido num desses diálogos demonstra a que nos referimos: "Roça orgânica é uma forma de externar aquilo que já fazemos com o babaçu, é uma forma de avançar o que já vínhamos [fazendo], é também ser professor para o governo, mostrar que quando a gente quer, faz."

O exercício da observação também tem sido uma prática nas nossas experiências de avaliação. Sempre procuramos marcar as entrevistas em momentos que ocorriam eventos como reuniões ou alguma atividade, de preferência, ainda que não necessariamente, previstas no plano de trabalho do projeto. Dessa forma, podíamos exercer uma observação (não camuflada) do grupo, sua forma de atuação, a prática do projeto. São nesses momentos em que se pode perceber em que medida aquela atividade é algo muito externo, difícil de ser apropriado pelo grupo e, portanto, de estabelecer um diálogo entre formas de conhecimento. Um dos casos marcantes foi uma capacitação dada por um especialista de uma agência multilateral de cooperação a um grupo de agricultoras, em que ensinava (no sentido de repassar um conhecimento) um procedimento para utilizar forragem armazenada para o gado em período de seca, que consistia em molhar a forragem com um produto químico misturado em água. ${ }^{11}$ Procedeu, então, à explicação para calcular a quantidade do produto que se deveria agregar, utilizando fórmulas matemáticas apresentadas em um quadro negro. O público sequer falava o mesmo idioma do técnico e a grande maioria não frequentou a escola. O diálogo simplesmente não aconteceu. Um exemplo extremo, mas que ilustra bem muitas das práticas no campo dos projetos de desenvolvimento.

Para contrabalançar, temos em mente a familiaridade com que uma mulher, líder de uma comunidade da periferia urbana de uma cidade de Pernambuco, transitava pela prefeitura e fazia demandas para sua comunidade. ${ }^{12}$ Poucos anos antes, tal comunidade sequer existia no mapa da prefeitura. Observar o seu trânsito e acompanhar reuniões de fóruns municipais dá uma

11 O projeto foi desenvolvido na década de 1990, na Bolívia, em uma comunidade rural indígena.

12 Referimo-nos aqui a um projeto de fortalecimento de organização de mulheres, voltado para o desenvolvimento local da comunidade, sobretudo no acesso a serviços públicos. Foi desenvolvido por uma organização feminista com apoio de uma agência de cooperação internacional na primeira década de 2000.

Horizontes Antropológicos, Porto Alegre, ano 20, n. 41, p. 117-140, jan./jun. 2014 
dimensão das novas configurações do contexto sobre o qual o projeto incidiu. Transitar pelas redes sociais que concretamente articulou seria dispensável - e muitas vezes o é - em projetos de avaliação. Contudo, a ressalva a ser feita é que, independentemente do projeto e da agência financiadora, os microprocessos sociais são, muitas vezes, mais reveladores e indicadores de mudanças em curso.

\section{0 antropólogo na avaliacão: a reafirmação do trabalho de campo e da teoria}

Nesse mundo, quanto mais crescem os conhecimentos, a necessidade vem junto. Vêm novos desafios que precisam de outros conhecimentos que surgem.

Mulher, quebradeira de coco babaçu.

Há uma especificidade na atuação de antropólogos, na avaliação de projetos sociais, que a diferencia de outras práticas “extramuros”, já objeto de reflexão na antropologia brasileira, como mencionado anteriormente. A mais tradicional, e talvez a que tem sido mais discutida, é a atuação de antropólogos na elaboração de laudos para demarcação de terras indígenas e quilombolas (Baines, 2004), ou ainda para atestar o uso tradicional de recursos da biodiversidade. De uma forma geral, o antropólogo é chamado como um profissional que já possui um conhecimento anterior daquele grupo social. Tanto que a Associação Brasileira de Antropologia chegou a criar um convênio com o Ministério Público para indicar tais profissionais, baseada no critério de possuir um conhecimento anterior do grupo em questão, conhecimento este construído através de pesquisas antropológicas dentro da tradição da disciplina (Feldman-Bianco, 2011).

Outra atuação é em agências da cooperação internacional, como especialistas no local e com capacidade de mediação, como reflete Leal (2010, p. 82-90). Também vinculados a áreas específicas, devido à sua formação e experiência de pesquisas anteriores, esses profissionais atuam na análise de projetos a serem financiados e em articulações políticas em temas de sua expertise.

Há ainda a atuação de antropólogos em ONGs, nem tão especializados, com um nível de comprometimento político mais forte, mas em precárias condições de trabalho, como relata Müller (2010, p. 89-96). 
Já experimentamos todas essas práticas e consideramos que a avaliação de projetos é um híbrido de cada uma dessas experiências e, ao mesmo tempo, não é nenhuma delas. Não é necessário ter expertise no tema ou grupo no qual o projeto atua, nem implica um compromisso político posterior. Há, supostamente, certa isenção em relação à agência de cooperação que apoia o projeto, e os limites éticos são bastante evidentes. A equação ética vem da nossa formação humanista, de uma postura política diante do discurso do desenvolvimento, de compromisso com a vida e o destino dos sujeitos que protagonizam o projeto avaliado. Nesse sentido, não deixa de ser uma antropologia da ação, na acepção dada por Roberto Cardoso de Oliveira (2004, p. 21) , que ressalta o caráter de prática social da disciplina, de "agir no mundo real”, de estar "comprometida não apenas com a busca de conhecimento sobre seu objeto de pesquisa, mas sobretudo com a vida dos sujeitos submetidos à observação".

Com efeito, o pressuposto da formação humanística não é garantidor da primazia da avaliação realizada pelo antropólogo em face de outros profissionais e disciplinas, especialmente, num momento bastante contemporâneo no qual a avaliação per se tende a tornar-se uma especialidade (assim como o gerenciamento de projetos) descolada de um contexto e de uma teoria social. Procuramos refletir sobre essa atuação a partir de uma questão: como fazer uma avaliação de um projeto de mudança social, tendo como fio condutor e expectativa de análise os parâmetros cartesianos e o predomínio de indicadores quantitativos de um marco lógico e de resultados esperados, com os instrumentos teóricos metodológicos da antropologia? Cada vez mais, reafirmamos nossa convicção de que a experiência de campo (antropológica) e a reflexão teórica anteriores são fundamentais. Com isso, queremos desencorajar que a avaliação de projetos seja concebida como uma prática isolada, especializada e até mesmo burocratizada (no sentido weberiano), integrando, por sua vez, o manual (e a seção final) do "project manager".

A prática da etnografia e o trabalho de campo afinam nossa sensibilidade. A teoria expande nosso olhar. A visão crítica ativa a curiosidade. $O$ "estrangeirismo” produz deslocamentos. Sem essa bagagem, facilmente nos enredamos nas armadilhas do discurso do desenvolvimento. 


\section{Referências}

BAINES, S. Antropologia do desenvolvimento e a questão das sociedades indígenas. Revista Anthropológicas, ano 8, v. 15, n. 2, p. 29-46, 2004.

BATESON, G. Steps to an ecology of mind. New York: Ballantine Books, 1972.

BARROSO HOFFMANN, M. Fronteiras étnicas, fronteiras de Estado e imaginação da nação: um estudo sobre a cooperação internacional norueguesa junto aos povos indígenas. Rio de Janeiro: E-papers; Laced. 2009.

CARDOSO DE OLIVIERA, R. O mal-estar da ética na antropologia prática. In: VÍCTORA, C. et al. Antropologia e ética: o debate atual no Brasil. Niterói: EdUFF, 2004. p. 21-32.

COSTA, D. M. Feminism and institutional development: women's NGOs in Brazil and Peru. In: BRASILEIRO, A. M. Women's leadership in a changing world. New York: UNIFEM, 1996. p. 44-61.

COSTA, D. M.; NEVES, G. H. Nuevas cuestiones en desarrollo: ONGs y género. Revista Pobreza Urbana \& Desarrollo, Buenos Aires, n. 11, p. 19-31, 1996.

COSTA, D. M.; NEVES, M. da G. R. das (Org.). Gênero e desenvolvimento institucional em ONGs. Rio de Janeiro: Ibam; Instituto de la Mujer, 1995.

COSTA, D. M.; NEVES, M. da G. R. das (Org.). Gênero e ONGs: propostas para o fortalecimento institucional. Rio de Janeiro: Ibam; The British Council, 1997.

ELIAS, N. Para a fundamentação de uma teoria dos processos sociais. In: NEIBURG, F.; WAIZBORT, L. (Org.). Escritos \& ensaios, 1: estado, processo, opinião pública/Norbert Elias. Rio de Janeiro: Jorge Zahar, 2006. p. 197-231.

ESCOBAR, A. Globalización, desarrollo y modernidad. In: ESCOBAR, A. et al. Planeación, participación y desarrollo. Medellín: Corporación Región, 2002. p. 9-32. 
ESCOBAR, A. El "postdesarrollo" como concepto y práctica social. In: MATO, D. (Coord.). Políticas de economía, ambiente y sociedad en tiempos de globalización. Caracas: Facultad de Ciencias Económicas y Sociales, Universidad Central de Venezuela, 2005. p. 17-31.

EVALPARTNERS. Evidence for the world we want: using evaluation to improve people's lives through better policy making. 2013. Disponível em: $<$ http://mymande.org/evalyear/Declaring_2015_as_the_International_Year_ of_Evaluation>. Acesso em: 30 ago. 2013.

FARIA, C. A. P. A política da avaliação de políticas públicas. Revista Brasileira de Ciências Sociais, v. 20, n. 59, p. 97-79, 2005.

FELDMAN-BIANCO, B. Entre a ciência e a política: desafios atuais da antropologia. Associação Brasileira de Antropologia, 30 ago. 2011. Disponível em: <http://www.abant.org.br/news/show/id/125>. Acesso em: 20 ago. 2013.

LEAL, O. F. Por uma antropologia não sitiada: o campo de atuação do antropólogo no mundo. In: TAVARES, F. et al. (Org.). Experiências de ensino e prática em antropologia no Brasil. Brasília: Ícone, 2010. p. 80-88.

MENDONÇA, P. M. E. (Coord.). Pesquisa arquitetura institucional de apoio às organizações da sociedade civil no Brasil: relatório final eixo cooperação internacional. São Paulo: CEAPG/FGV/; Articulação D3, 2012. Disponível em: <http://ceapg.fgv.br/sites/ceapg.fgv.br/files/arquivos/Pesquisa_Apoio_ OS/rf_eixo_coop_internac.pdf >. Acesso em: 15 ago. 2013.

MINAYO, M. C. de S. O desafio do conhecimento: pesquisa qualitativa em saúde. 8. ed. São Paulo: Hucitec, 2004.

MINAYO, M. C. de S.; DESLANDES, S. F. (Org.). Caminhos do pensamento: epidemiologia e método. Rio de Janeiro: Ed. Fiocruz, 2002.

MINAYO, M. C. de S. et al. (Org.). Avaliação por triangulação de métodos: abordagem de programas sociais. Rio de Janeiro: Ed. Fiocruz, 2005.

MÜLLER, C. B.Aprática antropológica: o desafio de trabalhar em organizações não-governamentais. In: TAVARES, F. et al. (Org.). Experiências de ensino e prática em antropologia no Brasil. Brasília: Ícone, 2010. p. 89-96. 
REVEL, J. (Org.). Jogos de escalas: a experiência da microanálise. Rio de Janeiro: Editora Fundação Getúlio Vargas, 1998.

REVISTA BRASILEIRA DE MONITORAMENTO E AVALIAÇÃO. Brasília: Ministério do Desenvolvimento Social e Combate à Fome; Secretaria de Avaliação e Gestão da Informação, 2011-.

SHORE, C.; WRIGHT, S. (Ed.). Anthropology of policy: critical perspectives on governance and power. London: Routledge, 1997.

SILVA, G. (Org.). Antropologia extramuros: novas responsabilidades sociais e políticas dos antropólogos. Brasília: Paralelo 15, 2008.

TAVARES, F. et al. (Org.). Experiências de ensino e prática em antropologia no Brasil. Brasília: Ícone, 2010.

TRIBUNAL DE CONTAS DA UNIÃO. Manual de auditoria operacional. Brasília, 2010.

VÍCTORA, C. et al. (Org.). Antropologia e ética: o debate atual no Brasil. Niterói: EdUFF, 2004. 